\title{
BMJ Open Quality Efficacy of an implementation package on documentation of central venous catheter insertions: an observational study
}

\author{
Erik Linné (D) , ${ }^{1}$ Maria Adrian, ${ }^{2,3}$ Peter Bentzer, ${ }^{1,2}$ Thomas Kander ${ }^{2,4}$
}

To cite: Linné $\mathrm{E}$, Adrian $\mathrm{M}$, Bentzer $\mathrm{P}$, et al. Efficacy of an implementation package on documentation of central venous catheter insertions: an observational study. BMJ Open Quality 2021;10:e01155. doi:10.1136/ bmjoq-2020-001155

- Additional supplemental material is published online only. To view, please visit the journal online (http://dx.doi.org/10. 1136/bmjoq-2020-001155)

Received 9 August 2020

Revised 5 April 2021

Accepted 19 April 2021
Check for updates

(C) Author(s) (or their employer(s)) 2021. Re-use permitted under CC BY-NC. No commercial re-use. See rights and permissions. Published by BMJ.

${ }^{1}$ Anaesthesiology and Intensive care, Helsingborgs lasarett, Helsingborg, Sweden

${ }^{2}$ Department of Clinical

Sciences, Lund University, Lund, Sweden

${ }^{3}$ Department of Cardiothoracic Surgery, Skåne University Hospital Lund, Lund, Skåne, Sweden

${ }^{4}$ Department of Intensive and Perioperative Care, Skåne University Hospital Lund, Lund, Skåne, Sweden

Correspondence to

Dr Erik Linné;

erik.linne@med.lu.se

\section{ABSTRACT}

Background Proper documentation of central venous catheter (CVC) insertions in electronic healthcare records is the basis for good follow-up and quality assurance. We have noted serious deficiencies in the documentation of CVC insertions and introduced an implementation package with the purpose of increasing the completeness of this documentation. The aim of the present study was to estimate the effect of the implementation package by assessing the proportion of missing data before and after the introduction of the implementation package.

Methods In this single centre observational study, data from CVC insertion templates in a common electronic health record were extracted and analysed after introducing the implementation package. The package included adoption of new local CVC-directions, a new updated CVC-insertion template in the regional common electronic health record and a review of all CVC-insertion templates with a reminder to the inserting physician to supplement missing data. The proportion of terms with missing data was reviewed and also compared with the proportion of missing data in a study prior to the introduction of the package.

Results In total, 7126 CVC-insertion templates were included. Of these $5539(78 \%)$ were without missing data for any of the 13 predefined variables. Completed insertion templates for three common terms increased from $38 \%$ prior to the introduction of the implementation package to $93 \%$, which represents an absolute reduction for missing data of $55 \%$ (95\% Cl $53 \%$ to $56 \%$, $p<0.0001)$. Conclusion The implementation package was highly effective in increasing the proportion of fully documented CVC insertions.

\section{INTRODUCTION}

In modern inpatient care, central venous catheters (CVCs) are essential but also associated with complications. Mechanical complications arise early after the insertion of a CVC and long-term complications, such as catheter-related infections, thrombosis and chronic venous stenosis, later in the course. CVC-related complications are associated with increased morbidity and mortality as well as increased costs. ${ }^{12}$

The basis to reduce healthcare related complications is high-quality documentation and follow-up of actions such as CVCinsertions. ${ }^{3}$ The American Society of Anesthesiologists Task
Force on Central Venous Access published practice guidelines suggesting checklists or protocol for placement and maintenance of CVCs and the Association of Anaesthetists of Great Britain and Ireland similarly recommends routines for management and documentation. ${ }^{5}$ The Swedish Society of Anaesthesia and Intensive Care (SFAI) and the Swedish Association of Local Authorities and Regions (SKR) recommend each department responsible for central venous catheterisation to perform continuous record keeping and quality control for all CVCs. ${ }^{6} 7$ Follow-up isn't easy and from an inquiry by SFAI in 2014 the scarcity of quality records and follow-up in Sweden was highlighted. ${ }^{6}$

At all hospitals in Region Skåne in southern Sweden, there is a well-established routine to document each CVC insertion in a template in the common electronic health record system (EHR). However, there is still a problem with missing data, which was demonstrated in a recent retrospective registry study by Björkander et al, based on over 10000 CVC insertions extracted from the EHR in the Region in question. ${ }^{8}$ In that study, one or more entries of clinically important variables were missing for $62 \%$ of the CVC insertions. In an attempt to improve quality-follow up of central venous catheterisation, we therefore introduced an implementation package in the Region, with the purpose to increase the proportion of completed CVG insertion templates in the EHR system.

The aim of this study was to estimate the effect of the implementation package by assessing the proportion of clinically relevant missing data before and after the introduction of the implementation package. The hypothesis was that the implementation package would decrease the proportion of missing data compared with a recently described historical control. ${ }^{8}$

\section{METHODS}

This retrospective observational study was approved by the Swedish Ethical Review 
Authority (registration number 2018-295) and was conducted in compliance with the Declaration of Helsinki. The Ethical Review Authority waived the requirement for written informed consent. The manuscript was prepared according to the Strengthening the Reporting of Observational Studies in Epidemiology guidelines for observational studies. ${ }^{9}$ Documentation of CVC insertions from eight hospitals in Region Skåne was collected. One university hospital with 1300 beds, three county hospitals with about 200 beds each, and four smaller hospitals with about 80 beds each. All documented CVC insertions on patients over 16 years of age, during the study period were considered for inclusion in the study. CVC insertions at the included departments were performed with full sterile precautions as previously described..$^{10}$ All CVC insertions were documented using a template in the EHR (Melior, North Kansas City, Missouri, USA) (see online supplemental file online). Data from the CVC insertion templates between 3 March 2019 and 2 March 2020 were extracted using an automated script and exported to Microsoft Excel V.2013 (Microsoft, Redmond, Washington, USA).

\section{Implementation package}

The implementation package included the following actions:

1. All CVC-responsible physicians at each hospital in the Region agreed on new local CVC directions complying with the CVC guidelines from the SKR and the SFAI. ${ }^{6} 7$

2. Based on national and regional guidelines the same CVC-responsible physicians agreed on a new updated CVC insertion template in the regional common EHR (see online supplemental file online). Each CVC responsible physician was responsible for informing all physicians and personnel affected by the changes at their own department. Means of dissemination of information was left to each responsible physician but was primarily done via personal and non-personal methods (ie, talks and email, respectively).

3. Since study launch in March 2019 all individual electronic GVC insertion templates were reviewed by dedicated research nurses or researchers for completeness. Based on previous studies, 13 predefined key variables were chosen and reviewed (table 1). ${ }^{11}$ The CVC inserting physicians were not aware of the 13 predefined key variables. However, if one or more of the key variables contained missing data, the CVC inserting physician was prompted by the dedicated research nurse/researcher to add this information.

\section{Outcomes}

Primary outcome was to assess the number of terms with missing data in the CVC insertion templates during the study period. Secondary outcome was to compare the proportion of terms with missing data with the same measurement in a previous study performed in the same cohort but prior to the introduction of the
Table 1 Thirteen predefined reviewed key variables from the CVC-insertion template

\begin{aligned} & \hline Variable \\ & \hline 2 Inserting physician \\ & \hline 3 Indication for CVC insertion \\ & \hline 4 Insertion time \\ & 5 Room for insertion \\ & \hline 6 Insertion technique \\ & \hline 7 Positive pressure ventilation \\ & \hline 8 Bore size/number of lumens \\ & 9 Catheter model/LOT* \\ & \hline 10 Catheter length \\ & \hline 11 Insertion related complication \\ & \hline 12 Number of - punctures through the skin \\ & \hline 13 Number of - punctures through the vessel \\ & \hline\end{aligned}

*Unique alpha numerical batch identifier.

CVC, central venous catheter.

implementation package. ${ }^{8}$ The 13 predefined key variables that were reviewed are listed in table 1 .

\section{Patient and public involvement}

Patients were not involved in the design of the study. However, the study was performed in the interest of patients receiving a CVC where it is of great importance to document the insertion procedure both in the interest of the specific patient but also for future patients as the insertion templates will be used as the basis for follow-up and quality assurance. Patients were not involved in the recruitment and conduct of the study.

\section{Statistics}

If all 13 predefined terms were without missing data, the template was considered complete. The terms with CVC information (bore size/number of lumens, catheter model/LOT and catheter length) was regarded as complete if either model or LOT were recorded. Templates containing bore size/number of lumens and catheter length, but missing model /LOT were regarded as complete if the CVC was inserted at a hospital where only one model with that combination of length and bore size was available.

The ratio of missing terms per CVC insertion template for each individual CVC inserting clinician was calculated and cases with a ratio greater than one was noted. To assess change in documentation of CVC insertions, the proportion of missing data after the introduction of the implementation package was compared with that reported in a previous study describing CVC documentation practices in all patients receiving CVC in the same hospitals between 2013 and 2016. ${ }^{8}$ Three common fields were compared ('Vascular insertion site', 'Catheter bore size/ number of lumens' and 'Number of punctures through 


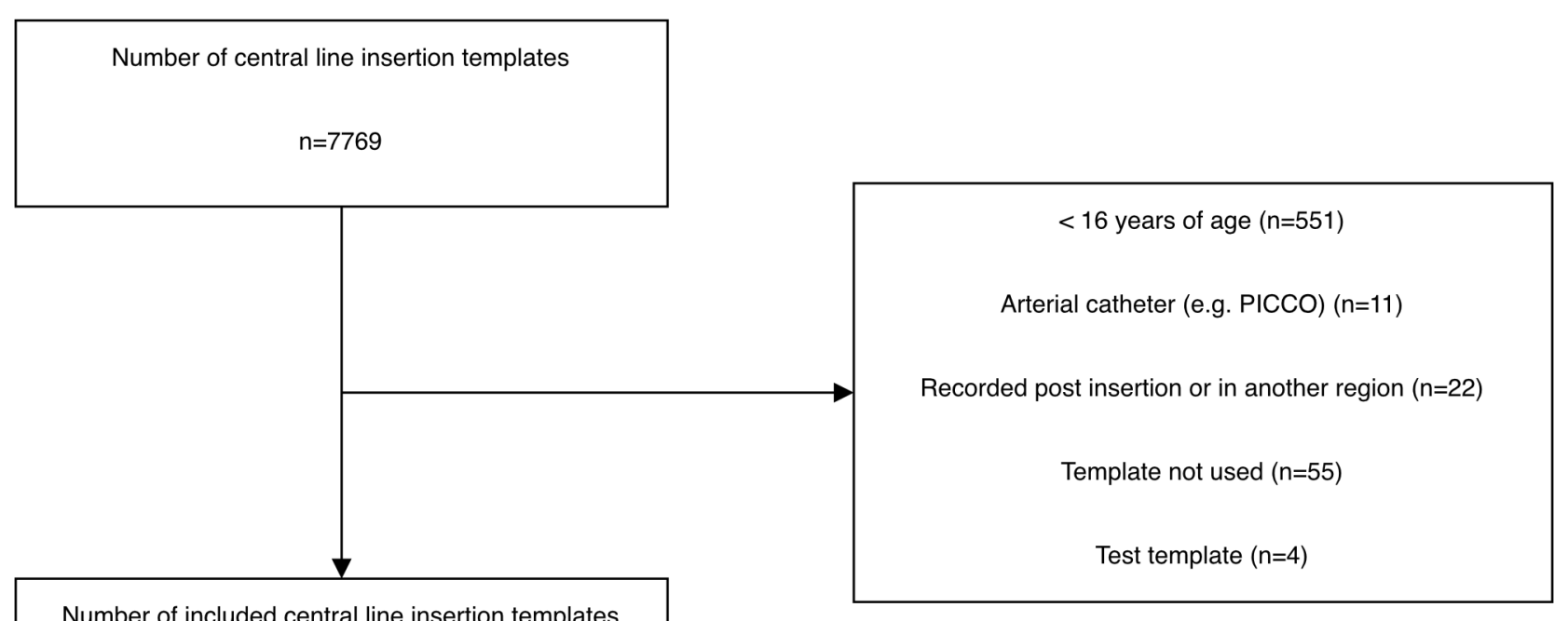

$\mathrm{n}=7126$

Figure 1 Flow chart.

skin'). In the previous study, these three variables were responsible for all of the missing data. ${ }^{8}$ The $\chi^{2}$ test was used to test for differences between observed frequencies. $\mathrm{P}$ values were not adjusted for multiple comparisons since the number of tests was limited.

Computer software used was Microsoft Excel 2013 and MedCalc (Online version, MedCalc Software Ltd, Ostend, Belgium). ${ }^{12}$

\section{RESULTS}

During the study period, a total of 7769 CVC insertion templates were reviewed (figure 1). Of these 5539 $(78 \%)$ were complete and $22 \%$ contained one or more missing fields (table 2). The most common missing field was 'Catheter model / LOT' (11\%) and the most uncommon field with missing data was 'Insertion time' $(2.3 \%)$. Only one field was missing in 852 cases which was $54 \%$ of all templates with missing data $(\mathrm{n}=1587)$. In $28 \%$ of the cases where data were missing in only one field, 'Catheter model / LOT' was liable (table 2). Between the first and second quarter there was a significant increase in the proportion of completed templates (72 vs $83 \%, \mathrm{p}<0.0001)$. From the second to the last quarter the proportion of completed templates stabilized around $80 \%$ (table 3 ).

Fifty-three out of the 317 CVC inserting physicians $(17 \%)$ had more than one term of missing data per central line insertion template. Completeness of documentation of GVC insertions increased from $38 \%$ in the historical $\mathrm{control}^{8}$ to $93 \%$ in the present study (table 4 ). This represents an absolute reduction for missing data of $55 \%$ (95\% CI $53 \%$ to $56 \%$ ) after the implementation package as compared with before $(\mathrm{p}<0.001)$.

\section{DISCUSSION}

In the present observational study, we demonstrate that an implementation package including introduction of an updated credible insertion template, delegated information responsibility to every separate department and

Table 2 Number of central venous catheter insertion templates with missing fields

\begin{tabular}{|c|c|c|}
\hline Templates & $n=7126(100)$ & $\mathrm{n}=852(100)$ \\
\hline Template field & Incomplete & $\begin{array}{l}\text { One missing } \\
\text { field }\end{array}$ \\
\hline Inserting physician & $382(5.4)$ & $107(13)$ \\
\hline Indication & $363(5.1)$ & $83(9.7)$ \\
\hline Insertion time & $164(2.3)$ & $32(3.8)$ \\
\hline Room for insertion & $267(3.7)$ & $33(3.9)$ \\
\hline Vascular insertion site & 235 (3.3) & $6(0.7)$ \\
\hline Insertion technique & $490(6.9)$ & $138(16.2)$ \\
\hline Anaesthetic method & $417(5.9)$ & $51(6)$ \\
\hline $\begin{array}{l}\text { Catheter bore size/number } \\
\text { of lumens }\end{array}$ & $376(5.3)$ & $0(0)$ \\
\hline Catheter length & $537(7.5)$ & $26(3.1)$ \\
\hline Catheter model and/or LOT & $785(11)$ & $235(28)$ \\
\hline $\begin{array}{l}\text { Insertion related } \\
\text { complication }\end{array}$ & $467(6.6)$ & $114(13.4)$ \\
\hline $\begin{array}{l}\text { Number of-punctures } \\
\text { through the skin }\end{array}$ & $418(5.9)$ & $6(0.7)$ \\
\hline $\begin{array}{l}\text { Number of-punctures } \\
\text { through the blood vessel }\end{array}$ & $451(6.3)$ & $21(2.5)$ \\
\hline $\begin{array}{l}\text { Number of templates with } \\
\text { any missing field }\end{array}$ & $1587(22)$ & - \\
\hline
\end{tabular}

Data are presented as numbers (\%). 
Table 3 Templates without missing fields

\begin{tabular}{ll}
\hline Time period & $\begin{array}{l}\text { Number of templates without } \\
\text { missing fields (\%) }\end{array}$ \\
\hline Entire study period & $5539(78)$ \\
\hline Q1* & $1296(72)$ \\
Q2 & $1290(83)$ \\
Q3 & $1510(83)$ \\
Q4 & $1443(80)$ \\
\hline
\end{tabular}

Data are presented as numbers (\%).

${ }^{*} \mathrm{Q} 1-\mathrm{Q} 4$, quarter $1-4$, quarters consisting of 3 months starting at the first day of the study period.

follow-up of every insertion template during a limited time, is highly effective in reducing missing data in CVC documentation. The hypothesis that the implementation package would decrease the proportion of missing data was confirmed. This high-quality documentation is a good basis for quality control of the CVC insertions and care as well as for the analyses of independent risk factors for mechanical complications within the ongoing observational study "CVC-MECH". ${ }^{11}$

Although the updated template was decided in a topdown manner it was well received. The CVC responsible physicians at each hospital were responsible for the update and for the information at each site. Further, also a bottom-up procedure was applied as all CVC inserting physicians were informed of the importance of feedback on the newly introduced template. An opportunity that many used, which further contributed to a high-quality template and a broad participation in the final design of the template.

There was a significant increase in the proportion of completely filled in templates between the first and second quarters, indicating that the implementation measures did not have effect immediately but with some delay. This may at least partly be explained by a delayed effect of the individual feedback to the inserting physician, given by dedicated research nurses or researchers.

It should also be noted that a relatively small share of the inserting physicians (17\%) accounted for all incomplete templates indicating that individual feedback and further reminders could be of use. It has previously been shown that the effect of such reminders is worthwhile and depend on frequency and timing. ${ }^{13}$
In implementation science the importance of a welldeveloped proposal to changes, strategies and maintenance of change, a planned time schedule and tasks, continuous monitoring, form of media or channel of distribution and determined responsibilities, are stressed. ${ }^{13}$ In the present implementation project, we have applied most of these principles. However, there are aspects which could be fine-tuned. For instance, a more structured dissemination strategy where affected personnel are updated regularly through means of talks and periodic emails containing progress and/or results of the implementation.

To the best of our knowledge this is the first report on the effectiveness of an implementation package on CVC-documentation. However, in accordance with the present study, a few studies in other fields of medicine have demonstrated that implementation of various types of EHR templates are an effective way to improve journal record quality. In a prospective study, implementation bundles including individual feedback improved readability of discharge instructions in a paediatric EHR from $13 \%$ to $98 \% .{ }^{14}$ Further, Dean et al demonstrated the importance of discharge summaries in the EHR and that these can be effectively implemented hospital-wide using evidence-based implementation strategies with both author and user satisfaction. ${ }^{15}$

Since many physicians involved in CVC insertions were aware of the fact that the templates were reviewed it is possible that a Hawthorne effect contributed to a higher share completed templates. ${ }^{16}$ It could also be argued that the Hawthorne effect has introduced a bias when comparing the proportion of filled out terms between the two time periods which in some sense is true but also a welcome effect that was consciously used to increase efficiency of the implementation.

As mentioned in the introduction, strong international and national recommendations on documentation and monitoring of central venous catheterisation exist. Further, according to the Swedish National Board of Health and Welfare, it's mandatory for physicians in Sweden to record invasive procedures like GVC insertions in the patient's medical record. ${ }^{17}$ The electronic CVC insertion template is the clinical documentation tool that all CVC operators at the participating hospitals are obligated to use. Since continuous recording and monitoring

\begin{tabular}{|c|c|c|c|}
\hline Template field & This study & Historical control $^{8}$ & $\mathbf{P}^{*}$ \\
\hline Templates & $\mathrm{n}=7126(100)$ & $n=10949(100)$ & \\
\hline Vascular insertion site & 235 (3.3) & $3288(30)$ & $<0.001$ \\
\hline Catheter bore size/number of lumens & $376(5.3)$ & $5694(52)$ & $<0.001$ \\
\hline Number of -punctures through skin & $418(5.9)$ & $4897(45)$ & $<0.001$ \\
\hline The three fields above complete & $6602(93)$ & $4203(38)$ & $<0.001$ \\
\hline
\end{tabular}

Data are presented as numbers (\%).

${ }^{*} \chi^{2}$ test. $P$ values are not corrected for multiple comparisons. 
of CVC insertions is essential for quality improvements, it is very important that persistent high-quality documentation is established.

We believe that the CVC insertion template implemented in this study enables high-quality prospective recording of relevant clinical data associated with central venous catheterisation. Adequate data registration in EHRs will in turn facilitate future studies and likely yield better results. Increased knowledge regarding complication rates and associated risk factors will contribute to quality improvements of CVC insertions and increased patient safety.

\section{Limitations}

The study is a post hoc analysis in a single healthcare system and hence there is a risk of bias and limited external validity. Even though there is a strong tradition in the studied departments to document every CVC insertion in the EHR, there may be a small number of CVCs that are not entered at all and therefore the number of incomplete entries may be underestimated. An estimation of the true number of undocumented CVC insertions could not be performed.

Further, due to an older insertion template in the study by Björkander $e t a l^{8}$ with data through 2016, it was not possible to compare the completion of all $13 \mathrm{key}$ terms before and after the introduction of the implementation package. Although we have no reason to suspect that the baseline from 2016 to the start of the present study has changed, this cannot definitely be ruled out.

Finally, it should be noted that the observational time may have been too short to definitely rule out a shortlived Hawthorne effect.

\section{CONCLUSION}

In this observational study, we have demonstrated that that an implementation package including introduction of an updated insertion template, delegated information responsibility and follow-up of every insertion template during a limited time, is highly effective in reducing missing data in CVC documentation.

Funding The authors have not declared a specific grant for this research from any funding agency in the public, commercial or not-for-profit sectors.

Competing interests None declared.

Patient consent for publication Not required.

Provenance and peer review Not commissioned; externally peer reviewed.

Data availability statement Data are available upon reasonable request. Data contains deidentified electronic health record data (central venous catheter insertion templates). Available from corresponding author (erik.linne@med.lu.se, https://orcid.org/0000-0002-5818-2498) to researchers with a methodologically reasonable proposal.

Supplemental material This content has been supplied by the author(s). It has not been vetted by BMJ Publishing Group Limited (BMJ) and may not have been peer-reviewed. Any opinions or recommendations discussed are solely those of the author(s) and are not endorsed by BMJ. BMJ disclaims all liability and responsibility arising from any reliance placed on the content. Where the content includes any translated material, BMJ does not warrant the accuracy and reliability of the translations (including but not limited to local regulations, clinical guidelines, terminology, drug names and drug dosages), and is not responsible for any error and/or omissions arising from translation and adaptation or otherwise.

Open access This is an open access article distributed in accordance with the Creative Commons Attribution Non Commercial (CC BY-NC 4.0) license, which permits others to distribute, remix, adapt, build upon this work non-commercially, and license their derivative works on different terms, provided the original work is properly cited, appropriate credit is given, any changes made indicated, and the use is non-commercial. See: http://creativecommons.org/licenses/by-nc/4.0/.

ORCID iD

Erik Linné http://orcid.org/0000-0002-5818-2498

\section{REFERENCES}

1 Polderman KH, Girbes AJ. Central venous catheter use. Part 1: mechanical complications. Intensive Care Med 2002;28:1-17.

2 Polderman KH, Girbes ARJ. Central venous catheter use. Part 2: infectious complications. Intensive Care Med 2002;28:18-28.

3 Campanella P, Lovato E, Marone C, et al. The impact of electronic health records on healthcare quality: a systematic review and metaanalysis. Eur J Public Health 2016;26:60-4.

4 American Society of Anesthesiologists. Practice guidelines for central venous access 2020: an updated report by the American Society of Anesthesiologists Task force on central venous access. Anesthesiology 2020;132:8-43.

5 Bodenham Chair A, Babu S, Bennett J, et al. Association of anaesthetists of great britain and ireland: safe vascular access 2016 . Anaesthesia 2016;71:573-85.

6 Svensk förening för anestesi och intensivvård. Riktlinjer för central venkateterisering [Internet], 2018. Available: https://sfai.se/wpcontent/uploads/2015/02/CVK_riktlinjer-inkl-Appendix.pdf [Accessed 1 Apr 2021].

7 Vårdhandboken [Internet]. Inera AB. Available: https://www. vardhandboken.se/katetrar-sonder-och-dran/central-venkateter/ oversikt/ [Accessed 1 Apr 2021].

8 Björkander M, Bentzer P, Schött U, et al. Mechanical complications of central venous catheter insertions: a retrospective multicenter study of incidence and risks. Acta Anaesthesiol Scand 2019;63:61-8.

9 Vandenbroucke JP, von Elm E, Altman DG, et al. Strengthening the reporting of observational studies in epidemiology (STROBE): explanation and elaboration. Epidemiology 2007;18:805-35.

10 Thorarinsdottir HR, Rockholt M, Klarin B, et al. Catheter-Related infections: a Scandinavian observational study on the impact of a simple hygiene insertion bundle. Acta Anaesthesiol Scand 2020;64:224-31.

11 Adrian M, Borgquist O, Bentzer $\mathrm{P}$, et al. Research protocol for mechanical complications after central venous catheterisation: a prospective controlled multicentre observational study to determine incidence and risk factors of mechanical complications within 24 hours after cannulation. BMJ Open 2019;9:e029301-6.

12 MedCalc Software. MedCalc's Free statistical calculators [Internet]. Available: https://www.medcalc.org/calc/index.php [Accessed $1 \mathrm{Apr}$ 2021].

13 Grol R, Wensing M, Eccles M. Improving patient care. Oxford, UK: John Wiley \& Sons, Ltd, 2013: 40. 19-20.

14 Unaka N, Statile A, Jerardi K, et al. Improving the readability of pediatric hospital medicine discharge instructions. J Hosp Med 2017;12:551-7.

15 Dean SM, Gilmore-Bykovskyi A, Buchanan J, et al. Design and Hospitalwide implementation of a standardized discharge summary in an electronic health record. Jt Comm J Qual Patient Saf 2016;42:555-AP11.

16 Sedgwick P, Greenwood N. Understanding the Hawthorne effect. BMJ 2015;351:h4672.

17 Swedish National Board of Health and Welfare (SOSFS 2008:1, 2011:9, 2013:6) [Internet]. Available: https://www.socialstyrelsen. se/regler-och-riktlinjer/foreskrifter-och-allmanna-rad/konsolideradeforeskrifter/20081-om-anvandning-av-medicintekniska-produkter-ihalso--och-sjukvarden/ [Accessed 1 Apr 2021]. 